Section Editor

Mitchell S.V. Elkind, MD, MS

\section{M.A. Almekhlafi, MD, FRCPC}

G. Williams, MD, FRCSC

F. Costello, MD, FRCPC

Address correspondence and reprint requests to $\mathrm{Dr}$. Mohammed A. Almekhlafi, Department of Clinical Neurosciences, University of Calgary, Foothills Medical Centre, 1403-29 St NW, Calgary, AB T2N 2T9 Canada malmekhl@ucalgary.ca

Clinical Reasoning:

\title{
Optic disc swelling in a patient with AIDS
}

Figure 1 Imaging

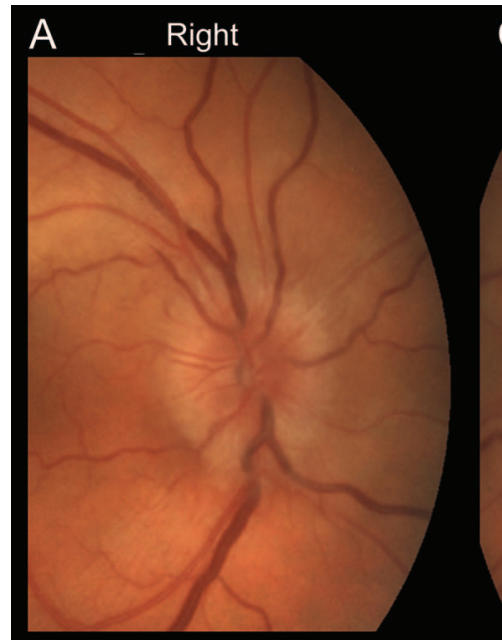

C Left

B

D

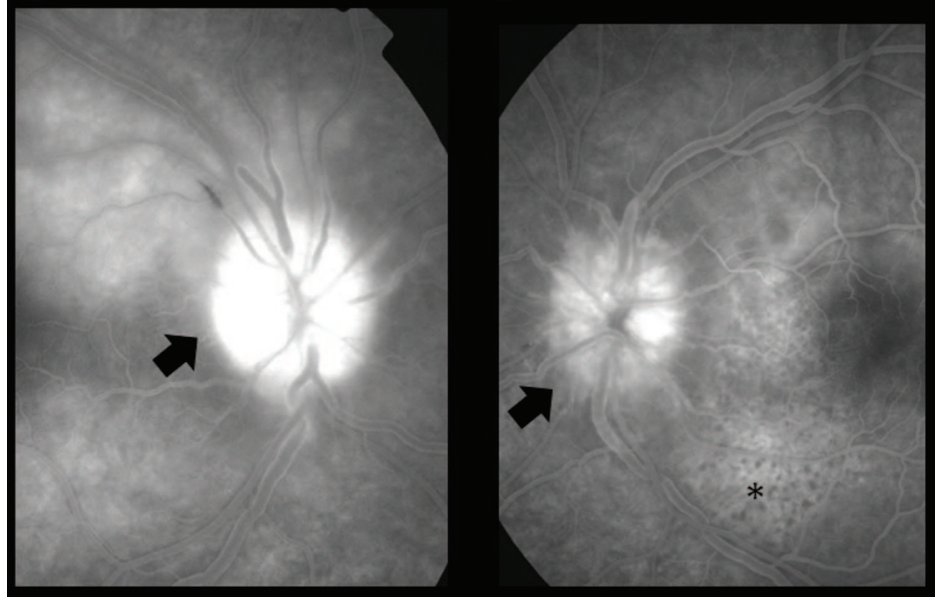

Ophthalmoscopic photographs (A, C) show bilateral elevated optic discs with no evidence of hemorrhage or exudates. Fluorescein angiogram (B, D) shows optic nerve hyperfluorescence bilaterally (arrows) with left stippled hypofluorescent spots representing choroidal leakage with nonfilling infiltrates ( $D$, asterisk).

\section{SECTION 1}

A 51-year-old man, known to have AIDS and hepatitis $\mathrm{C}$, presented with a 1-week history of painless blurred vision in the left eye. He denied any symptoms of raised intracranial pressure including head- ache, pulse-synchronous tinnitus, transient visual obscurations, or diplopia.

Two months prior, he developed pain in his lower back radiating into both legs and an associated band-like sensation around his waist. He ini- 
tiated a course of oxycodone medication, and the pain subsided in 4 weeks.

On examination, he was normotensive. Visual acuity was 20/20 in the right eye and 20/150 in the left. There was no relative afferent pupil defect (RAPD). Color vision was normal in the right eye (17/17 Hardy Rand and Rittler HRR pseudoisochromatic plates) and absent in the left eye $(0 / 17$ HRR plates). Ophthalmoscopy showed marked bilateral optic disc swelling (figure 1, A and C) and macular edema in the left eye. Visual field testing showed a small inferotemporal scotoma in the right eye, with a larger central scotoma in the left eye. Ocular motility and external ocular examinations were normal. There was subjective decrease in light touch and pinprick sensations up to the midshin level bilaterally. There was no spinal sensory level. Deep tendon reflexes were present throughout with flexor plantar responses. The patient's CD4 count was 189 cells $/ \mathrm{mm}^{3}$.

\section{Questions for consideration:}

1. What is your differential diagnosis at this point?

2. What initial investigations would you order? 


\section{SECTION 2}

Bilateral optic disc edema is an alarming sign, particularly in this patient with AIDS. It commonly indicates raised intracranial pressure (ICP) due to a space-occupying lesion, a CNS infection, or an obstruction of venous or CSF flow. However, uncomplicated papilledema is not typically associated with reduced visual acuity or dyschromatopsia.

Differential diagnosis includes chronic meningitis due to fungal infections, which can cause subacute increase in ICP. Primary CNS lymphoma (PCNSL) causes disc edema through increased ICP or direct infiltration of the optic nerve. Lymphoma can also invade the meninges, producing multiple cranial neuropathies and polyradiculopathies. This patient had a history suggestive of prior polyradiculopathy, but the spontaneous resolution of his symptoms was atypical of lymphoma.

Bilateral simultaneous or sequential optic neuropathy due to inflammation (as in neuromyelitis optica, sarcoidosis, and Wegener granulomatosis) is not typ- ically associated with HIV infection. Infections such as cryptococcus, toxoplasmosis, tuberculosis, herpes zoster, cytomegalovirus, and herpes simplex virus can also affect the optic nerves or the retina. Syphilis is another potential etiology for optic neuropathy in the setting of HIV infection.

Enhanced MRI scan of the brain and entire spinal cord did not demonstrate any pathology. There was no evidence of venous sinus thrombosis or abnormal meningeal enhancement. Lumbar puncture yielded a slightly high opening pressure $\left(27 \mathrm{~cm} \mathrm{H}_{2} \mathrm{O}\right)$, high white cell count $(21.1 / \mu \mathrm{L}$ [76\% lymphocytes]), elevated protein $(1.12 \mathrm{~g} / \mathrm{L})$, and glucose of $3.1 \mathrm{mmol} / \mathrm{L}$ (serum glucose $7.2 \mathrm{mmol} / \mathrm{L}$ ). CSF was negative for a comprehensive viral PCR panel, Cryptococcus antigen, bacterial cultures, acid-fast bacilli, and cytology.

\section{Questions for consideration:}

1. How do these results change your differential diagnosis?

2. What additional investigations would you consider? 


\section{SECTION 3}

The abnormal CSF with lymphocytic pleocytosis and low glucose can be seen in fungal and mycobacterial infections. However, the opening pressure associated with these conditions is typically much higher than that observed in this case. Although HIV can cause CSF pleocytosis and elevated protein, cell counts higher than $20 / \mu \mathrm{L}$ are considered significant. ${ }^{1}$ In addition, viral infections do not classically lower the CSF glucose level. PCNSL is still a potential etiology for this clinical presentation, despite normal imaging.

To better tailor further workup, reconsideration of the localization of the problem is important. Although reduced visual acuity and color vision in the context of optic disc edema suggest an optic nerve problem, the lack of RAPD in the left eye argues against this localization because it indicates relatively symmetric function between both optic nerves. Processes affecting the afferent visual pathway posterior to the chiasm should produce visual field deficits that respect the vertical meridian in both eyes. The field defects in this case crossed the vertical meridian, indicating a process affecting the visual pathway anterior to the chiasm. Therefore, given the lateralizing defects in visual acuity, visual field sensitivity, and color vision in the left eye, further assessment of the anterior and posterior segments, with focused examination of the macular regions, is necessary to identify any pathology and to elucidate the mechanism of vision loss in this case.

Assessment of the anterior segment was normal. In addition to the optic disc edema, there was a slightly creamy appearance to the choroid around the disc, greater in the left than the right eye. Fluorescein angiogram showed an infiltrative process around the optic nerves in both eyes, and extension through the macula in the left eye (figure 1, B and D).

\section{Question for consideration:}

1. What tests would you consider now? 


\section{SECTION 4}

This infiltrative picture is atypical for cytomegalovirus, varicella zoster virus, or toxoplasmosis. The differential diagnosis of this appearance is limited given the patient's HIV status. Possibilities include lymphoma and syphilis.

Further testing showed a reactive plasma syphilis antibody that was confirmed with enzyme immunoassay. Although syphilis serology does not differentiate active disease from previous infection, this man was known to have unreactive syphilis testing in the recent past.

He was treated with parenteral penicillin with significant improvement in his visual symptoms. When assessed in follow-up after 2 months, his visual acuity was 20/20 in both eyes. He had minor reduction in color vision in the left eye. Fundus examination demonstrated mild optic disc hyperemia bilaterally (figure e-1 on the Neurology ${ }^{\circledR}$ Web site at www.neurology.org).

DISCUSSION Neurosyphilis has a broad clinical picture. In the early infection phase, acute meningitis, meningovasculitis, and myelitis have been described. Cognitive impairment (general paralysis of the insane) and tabes dorsalis, characterized by sensory ataxia and lancinating pains, are seen in the late stages of the disease. ${ }^{2}$

Ocular syphilis is a rare complication of HIV infection, occurring in fewer than $1 \%$ of patients. ${ }^{3}$ However, about $10 \%$ of patients with syphilis develop ocular involvement, with posterior uveitis being the most common presentation. ${ }^{4}$ The neuroophthalmologic manifestations include Argyll Robertson pupil (unilateral or bilateral light-near dissociation in small pupils), ocular motor nerve palsies, papillitis, optic neuritis, and optic perineuritis. ${ }^{5}$ Given the reversibility of these changes with treatment, detailed ophthalmologic examination is essential in all cases of suspected ocular syphilis.

The diagnosis of syphilis is based on serology. This can pose a challenge in the immunocompromised patient since serology relies on the immune response to the infection. A reactive CSF-Venereal Disease Research Laboratory (VDRL) testing establishes the diagnosis of neurosyphilis in the absence of CSF contamination with blood. ${ }^{6}$ However, the test lacks sensitivity, as up to $70 \%$ of neurosyphilis patients test negative, especially in the early stages. ${ }^{2,7}$ In these circumstances, the fluorescent treponemal antibodyabsorbed (FTA-ABS) test is a more sensitive, but less specific, test than the CSF-VDRL. ${ }^{8}$ Other clues include CSF lymphocytic pleocytosis ( $>20$ cells $/ \mu \mathrm{L}$ in HIVpositive patients) and elevated CSF protein, which is less specific than pleocytosis. ${ }^{1}$ Therefore, the diagnosis of neurosyphilis in patients with HIV relies on the proper interpretation of a combination of clinical, serologic, and CSF studies.

The treatment for neurosyphilis and ocular syphilis is similar. The recommended regimen is parenteral penicillin $G$ administered as 3-4 million units every 4 hours (or continuous infusion of 18-24 million units per day), for 10-14 days. ${ }^{6}$ Treatment response can be assessed clinically and followed using serum rapid plasma reagin (RPR) titer. Alternatively, if CSF pleocytosis was present initially, serial CSF examination can be performed every 6 months until the cell count normalizes. Changes in CSF-VDRL or CSF protein are much slower than cell count and may even persist in those with more advanced immunosuppression. ${ }^{9}$ In immunocompetent patients and HIV-positive patients on highly-active antiretroviral therapy, normalization of the serum RPR titer was found to predict normalization of clinical and CSF abnormalities, with the exception of CSF protein, in more than $80 \%$ of 110 patients at 4 months. ${ }^{9}$ Retreatment should be considered if the cell count is persistently high after 6 months or if the CSF cell count or protein is not normal after 2 years. ${ }^{6}$

\section{AUTHOR CONTRIBUTIONS}

Dr. Almekhlafi: concept and drafting of the manuscript. Dr. Williams: critical review of the manuscript and review of the literature. Dr. Costello: drafting and critical review of the manuscript.

\section{DISCLOSURE}

Dr. Almekhlafi reports no disclosures. Dr. Williams serves on scientific advisory boards for Bausch + Lomb, Novartis, Regeneron Pharmaceuticals, Inc. (Bayer Schering Pharma), and Arctic DX; has received an honorarium from Novartis; serves as a consultant for Bausch + Lomb; serves on the speakers' bureau for Novartis; and interprets fluorescein angiography (2\% clinical effort) at Rockyview General Hospital. Dr. Costello has received research support from the MS Society of Canada and Neuroscience Canada.

\section{REFERENCES}

1. Marra CM, Maxwell CL, Collier AC, Robertson KR, Imrie A. Interpreting cerebrospinal fluid pleocytosis in HIV in the era of potent antiretroviral therapy. BMC Infect Dis 2007;7:37.

2. Ghanem KG. Neurosyphilis: a historical perspective and review. CNS Neurosci Ther 2010;16:e157-e168.

3. Biotti D, Bidot S, Mahy S, et al. Ocular syphilis and HIV infection. Sex Transm Dis 2010;37:41-43.

4. Balba GP, Kumar PN, James AN, et al. Ocular syphilis in HIV-positive patients receiving highly active antiretroviral therapy. Am J Med 2006;119:448.

5. Gaudio PA. Update on ocular syphilis. Curr Opin Ophthalmol 2006;17:562-566.

6. Workowski KA, Berman S. Sexually transmitted diseases treatment guidelines. MMWR Recomm Rep 2010;59:1-110.

7. Hart G. Syphilis tests in diagnostic and therapeutic decision making. Ann Intern Med 1986;104:368-376.

8. Marra CM, Tantalo LC, Maxwell CL, Dougherty K, Wood B. Alternative cerebrospinal fluid tests to diagnose neurosyphilis in HIV-infected individuals. Neurology 2004;63:85-88.

9. Marra CM, Maxwell CL, Tantalo L, et al. Normalization of cerebrospinal fluid abnormalities after neurosyphilis therapy: does HIV status matter? Clin Infect Dis 2004;38:1001-1006. 


\title{
Neurology
}

\author{
Clinical Reasoning: Optic disc swelling in a patient with AIDS \\ M.A. Almekhlafi, G. Williams and F. Costello \\ Neurology 2011;77; e28-e32 \\ DOI 10.1212/WNL.0b013e318227b1d4
}

This information is current as of August 1, 2011

\section{Updated Information \& Services \\ Supplementary Material \\ References \\ Subspecialty Collections}

Permissions \& Licensing

Reprints including high resolution figures, can be found at:

http://n.neurology.org/content/77/5/e28.full

Supplementary material can be found at:

http://n.neurology.org/content/supp1/2011/07/31/77.5.e28.DC1

This article cites 9 articles, 1 of which you can access for free at: http://n.neurology.org/content/77/5/e28.full\#ref-list-1

This article, along with others on similar topics, appears in the following collection(s):

\section{All Infections}

http://n.neurology.org/cgi/collection/all_infections

All Neuro-ophthalmology

http://n.neurology.org/cgi/collection/all_neuroophthalmology

HIV

http://n.neurology.org/cgi/collection/hiv

Optic nerve

http://n.neurology.org/cgi/collection/optic_nerve

Information about reproducing this article in parts (figures,tables) or in its entirety can be found online at:

http://www.neurology.org/about/about_the_journal\#permissions

Information about ordering reprints can be found online:

http://n.neurology.org/subscribers/advertise

Neurology ${ }^{\circledR}$ is the official journal of the American Academy of Neurology. Published continuously since 1951, it is now a weekly with 48 issues per year. Copyright Copyright (? 2011 by AAN Enterprises, Inc.. All rights reserved. Print ISSN: 0028-3878. Online ISSN: 1526-632X.

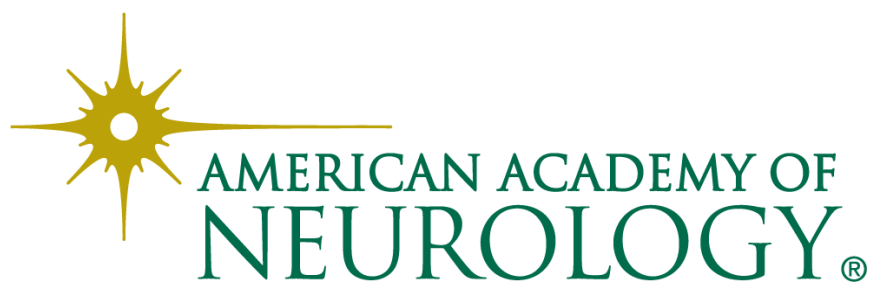

